Article

\title{
A Forecasting Method for Harmful Algal Bloom(HAB)-Prone Regions Allowing Preemptive Countermeasures Based only on Acoustic Doppler Current Profiler Measurements in a Large River
}

\author{
Geunsoo Son ${ }^{1}$, Dongsu Kim ${ }^{1, *}$, Young Do Kim ${ }^{2} \mathbb{D}$, Siwan Lyu ${ }^{3}$ (D) and Soojeong Kim 4 \\ 1 Department of Civil and Environmental Engineering, Dankook University, 152 Jukjeon-ro, Suji-gu, \\ Yoingin-si, Gyeonggi-do 16890, Korea; geunsoo87@dankook.ac.kr \\ 2 Department of Civil and Environmental Engineering, Myongji University, 116 Myongi-ro, Cheoin-gu, \\ Yoingin-si, Gyeonggi-do 17058, Korea; ydkim@mju.ac.kr \\ 3 Department of Civil Engineering, Changwon National University, 20 Changwondaehak-ro, Uichang-gu, \\ Changwon-si, Gyeongsangnam-do 51140, Korea; siwan@changwon.ac.kr \\ 4 University College, Yonsei University, 85, Songdogwhak-ro, Yeonsu-gu, Incheon 21983, Korea; \\ soojkim@yonsei.ac.kr \\ * Correspondence: dongsu-kim@dankook.ac.kr; Tel.: +82-31-8005-3611
}

Received: 23 September 2020; Accepted: 5 December 2020; Published: 11 December 2020

\begin{abstract}
Harmful algal blooms (HABs) have been recognized as a serious problem for aquatic ecosystems and a threat to drinking water systems. The proposed method aimed to develop a practical and rapid countermeasure, enabling preemptive responses to massive algal blooms, through which prior to the algal bloom season we can identify HAB-prone regions based on estimations of where harmful algae initiates and develops significantly. The HAB-prone regions were derived from temperature, depth, flow velocity, and sediment concentration data based only on acoustic Doppler current profilers (ADCPs) without relying further on supplementary data collection, such as the water quality. For HAB-prone regions, we employed hot-spot analysis using K-means clustering and the Getis-Ord $G^{*}$, in conjunction with the spatial autocorrelation of Moran's I and the local index of spatial association (LISA). The validation of the derived HAB-prone regions was conducted for ADCP measurements located at the downstream of Nam and Nakdong River confluence, South Korea, which preceded three months of algal bloom season monitored by unmanned aerial vehicles (UAVs). The visual inspection demonstrated that the comparison resulted in an acceptable range of agreement and consistency between the predicted HAB-prone regions and actual UAV-based observations of actual algal blooms.
\end{abstract}

Keywords: harmful algal bloom; ADCP; hot-spot; river; preemptive countermeasures

\section{Introduction}

Recently, rivers have faced unprecedented challenges in coping with harmful algal blooms (HABs) due to substantial human interventions in natural rivers, including dam construction, agricultural development, and urbanization, which have led to significant changes and the formation of ideal environmental conditions for HABs. Subsequent changes in the water quality of rivers due to algal blooms in water bodies are emerging as a critical problem. For instance, the installation of 15 large weirs after the four major river projects in South Korea has maintained certain water levels which has led to substantially reduced streamflow velocities and nutrient accumulation. Consequently such environmental change has yielded an unprecedented harmful algal bloom (HAB) such as cyanobacteria 
by promoting eutrophication in these water bodies [1,2]. Cyanobacterial algal blooms refer to a phenomenon in which eutrophic lakes or slowly flowing rivers are characterized by the multiplication of algae multiply and its accumulation in large amounts on the surface of the water, which alters the color of the water to green. Flourishing algal blooms have been reported to have adverse effects on the aquatic ecosystem by consuming large amounts of oxygen during decay, thus reducing the dissolved oxygen (DO) in the water. Therefore, algal blooms have a negative effect on water quality and may adversely affect organisms in aquatic ecosystems, such as invertebrates and fish in water bodies. These HABs are recognized as a serious problem for river water quality management because of their effects on aquatic ecosystems [3] and threat to drinking water systems. In particular, harmful blooms of cyanobacteria can cause serious problems in industrial, domestic, and agricultural water supplies, thus requiring analyses of the causes and countermeasures for HABs for water quality management [4]. Hence, we must identify the causes of cyanobacterial blooms to protect ecosystems through effective water quality management.

For harmful algal blooms in riverine systems, previous studies have suggested that nutrients, water temperature, and sunlight are the three major triggers for the generation of HABs [5-8]. Thus, HABs can be prevented by controlling these three conditions, in which sunlight control is almost impossible. Increasing the water volume and building large dams can help lower the water temperature, but increasing the water volume can reduce the water flow, which can create a favorable environment for the propagation of algae via nutrient accumulation [9]. In South Korea, after the four major river construction projects, the water volume of the mainstream has increased, but the flow velocity has substantially decreased to almost stagnant flow conditions. The occurrence of algae due to an increased residence time has recently been reported as the most significant problem for the water quality management of rivers [10].

The vast majority of previous studies have been based on conventional point-based sporadic monitoring of HAB cell numbers with sampling time intervals mostly relying on direct in situ sampling [11-14]. The recent advent of remote sensing methods, such as aerial hyperspectral images, has enabled researchers to capture the spatial extent of algal blooms and their evolution at a significant degree of accuracy [15-20]. In particular, aerial survey equipment using unmanned aerial vehicles (UAVs) has been widely applied to monitor and investigate HABs in rivers and lakes [17,18,21-29]. However, we note that despite their high potential, remote sensing approaches are still under development and are currently not widely applied by practitioners, as well having notable limitations in that these approaches are only applicable when algal blooms are already substantial or at least have begun to bloom. In terms of forecasting HABs, various numerical models have been established and received significant improvements, allowing us to investigate how HABs will react and propagate in specific aquatic environments $[18,21,30]$. However, numerical models are still limited by their ability to sufficiently prove their performance in terms of numerous situations, where the underlying assumptions of numerical modeling are violated and sometimes differ drastically between the modeled and in situ data. In contrast, based only on in situ measurements, the ability to specify HAB-prone regions is of significant interest even before substantial algal blooms develop by evaluating various relevant parameters known to affect HABs, such as nutrients, temperature, flow speed, bathymetry, and turbidity, among others. Such detailed spatial observations of in situ data covering an ample area of large rivers, which can satisfy spatial resolution standards without relying on remote sensing, have been nearly impossible with classic point-based methods or inevitably require expensive instruments, significant funding, and laborious field work; therefore, only limited attempts have been made to date. This is because multiple types of hydrometric and water quality sensors should be intensively utilized. Despite extensive efforts to determine appropriate methods for practical situations, few data-driven approaches have been developed, which have been subsequently regarded as not feasible. Therefore, in the present context, we must develop such methods in a plausible cost-benefit manner.

In this study, we propose a practical method to identify HAB-prone regions in riverine environments even before algal blooms develop using only acoustic Doppler current profilers (ADCPs) 
and applying subsequent machine-learning spatial clustering techniques. ADCPs have been used in riverine observations for several decades, especially for streamflow discharge in its initial stages to establish a classic rating curve and support various hydromorphologic studies. Presently, ADCPs have been well accepted in hydrometric communities, such that that they have become universal in terms of riverine monitoring. In addition to flow velocity measurements using the Doppler effect, we emphasize the fact that ADCPs provide other parameters associated with algal blooms: bathymetry, temperature, and suspended sediment concentrations [31,32]. Beside direct measurements by ADCPs, suspended sediment concentrations considered that the intensity of the backscattered ultrasonic signal tends to be proportional to the amount of suspended matter, including sediment and dissolved aquatic materials, and recent such efforts to use ADCPs to spatially map suspended materials have begun to attract attention in hydrometric communities. We hypothesize that these parameters, spatially assessed only by ADCPs (i.e., velocity, bathymetry, temperature, and sediment), can be strongly commensurate with the occurrence of algal blooms, even when certain other relevant parameters, such as the water quality index of nutrients and the sunshine rate, are not available. If even limited parameters, provided only by ADCPs, are capable of deriving HAB-prone regions with a plausible degree of accuracy, with a lack of water quality data, which are usually not spatially available, this approach can have practical significance from a cost-benefit perspective and can be readily used by engineers.

The spatial prediction of HAB-prone regions using the data measured only with an ADCP was performed with "hot-spot" analyses through K-means clustering [33], as well as the Getis-Ord method $[34,35]$. Before conducting the hot-spot analysis to determine the HAB-prone regions, we must check whether spatially variant in situ ADCP data contain spatial similarities with their neighborhood data (i.e., spatial autocorrelation) or if they are randomly distributed. To yield spatial autocorrelation, Moran's I concept [36] was applied in this study. Similarly [37] quantitatively analyzed the changes in the spatial distribution patterns in marine environments through spatial autocorrelation to understand the spatio-temporal patterns in marine environments. [38] utilized spatial autocorrelation to relate the spatial correlation of algae observed along a stream in Namdaecheon. Currently, the K-means algorithm has been widely used to predict and classify water quality in rivers and oceans [39-41]. As another method of delineating HAB-prone regions, this study also applied a hot-spot analysis based on the Getis-Ord $G^{*}$ method [34,35]. Reference [42] analyzed the spatio-temporal patterns of environmental pollution incidents between 1995 and 2012 using the Getis-Ord G* method.

Collectively, this study took advantage of the full capability of ADCP, such as the flow velocity, depth, temperature, and backscatter, which can explain the physicochemical factors that affect algal blooms. On this basis, the goal of this study is to provide a practical technique to rapidly forecast HAB-prone regions by performing hotspot analysis through the HAB hotspot index, which combines spatial autocorrelation analysis and measurement results based on the K-means cluster analysis and Getis-Ord $\mathrm{G}^{*}$ statistic. The proposed method was validated in a study area located at the downstream of the confluence between the Nam and Nakdong river historically known to be susceptible to HABs during the summer season, especially after the construction of the Haman and Hapcheon weirs in 2012, which transformed Nakdong River into a stagnant area capable of storing more water than before. Recently, this area has posed special attention in terms of water quality management by a Chilseo water intake that has taken responsibility as the drinking water supplier to adjacent large cities, such as Daegu and Busan, with a multi-million population, but has suffered severely from annual algal blooms during the summer.

\section{Materials and Methods}

\subsection{Study Area}

The study area used to derive HAB-prone regions is approximately $10 \mathrm{~km}$ of a reach of a river immediately downstream of the confluence of the Nakdong and Nam rivers in the direction of Haman weir (see Figure 1a,b). More specifically, the river width of Nakdong River is approximately $350-400 \mathrm{~m}$ 
in the upper part of the reach and approximately $650 \mathrm{~m}$ in the lower part. The mean bathymetry and flow speed are 4-5 m and less than $0.1 \mathrm{~m} / \mathrm{s}$, respectively. In the downstream direction, the bathymetry gradually decreases with an increase in the width of the river. As a result, the water surface temperature shows a tendency to rise downstream, considering that the water temperature is related to the relative depth of the water. We note that the confluence with a tributary, i.e., Nam River, which originates from Jiri Mountain and is generally clearer than the main channel, may have an influence on the reduction of algal blooms in the direct intrusive and mixing regions.
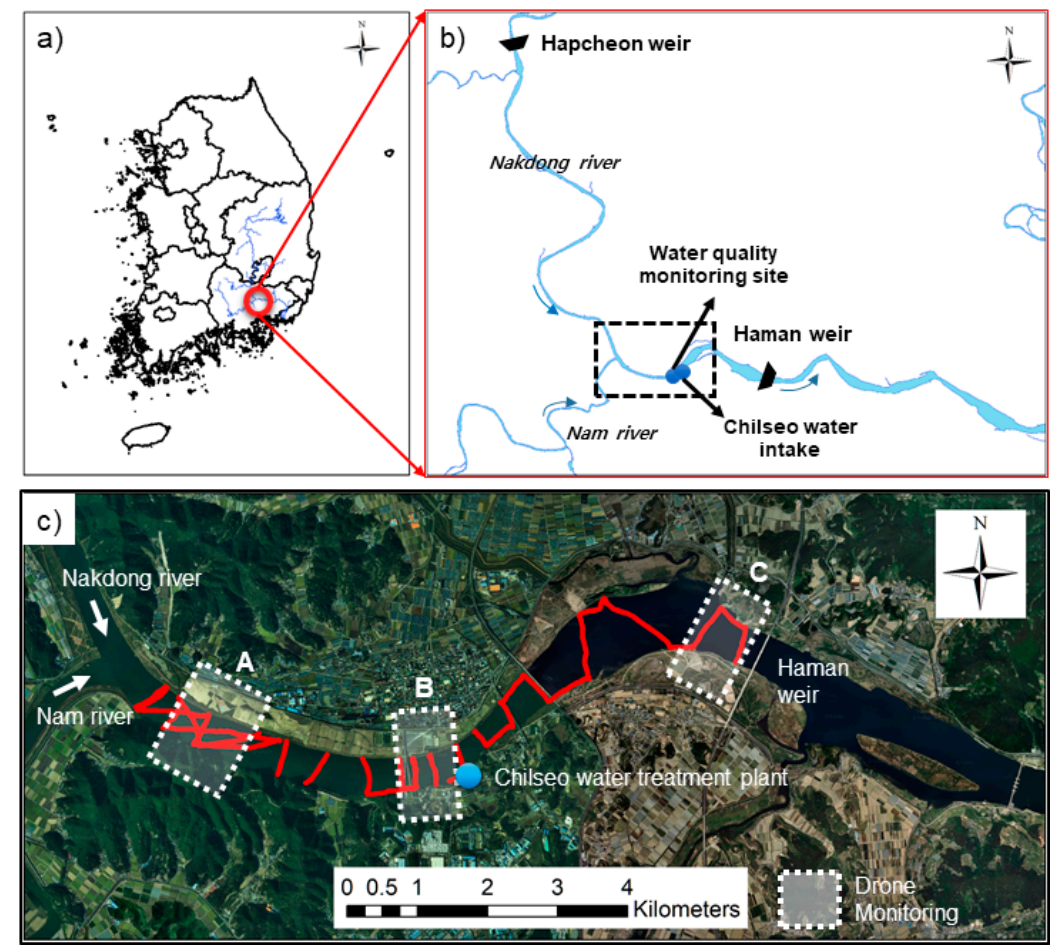

Figure 1. The study area of downstream vicinity of the Nam and Nakdong river confluence where three months of ADCP and UAV measurements were carried out simultaneously: (a) the location of the study area in southeastern South Korea; (b) the study area, in the black dashed line box, and the locations of the water quality monitoring site operated by the government, Chilseo water intake, and Haman weir, recently installed as part of the four major rivers project at the top of the planform with the confluence; and (c) locations of the ADCP measurements (red dots) before algal bloom development and aerial monitoring with a UAV (white dots) during mid-point of algal bloom development during the subsequent three months with similar streamflow conditions.

\subsection{Field Measurements}

The ADCP (SonTek RiverSurveyor M9, SonTek, San Diego, CA, USA) mounted on a boat was operated in various cross-sections covering the entire study area, as illustrated by the red line in Figure 1c, during which the bathymetry, velocity, temperature, and backscatter were concurrently measured or derived along the paths illustrated in Figure 1c. An ADCP measurement campaign was conducted on 28 April 2016, before the development of HABs. During the middle of the algal bloom period on 14 August 2016, airborne monitoring with UAV (DJI Fathom IV) was carried out in certain areas, as shown in Figure 1c, to visually verify the derived HAB-prone regions based on the ADCP survey. Figure 2 specifies the in situ conditions at the moment of both measurement campaigns from various perspectives of the streamflow discharge, rainfall, temperature, and algal concentration (cells/L), which was derived from public data available from the Korean National Water Quality and Quantity Monitoring Network (http://water.nier.go.kr/ publicMain/mainContent.do). The maximum number of cyanobacterial alage in 2016 in this region reached nearly 200,000 cell/mL which corresponded to 
massively algal bloom, where water temperature was around $30^{\circ} \mathrm{C}$. The study area in the Nakdong River usually showed relatively high nitrate and phosphorous level since the rural area surrounded this region. Based on Figure $2 b$, the UAV monitoring was conducted when the temperature almost reached its peak, but the algal cell number remained at the mid-point of their ascent to the peak, where no rain occurred and streamflow was nearly stagnant. As mentioned earlier, identification of HAB-prone regions in this study was intended to be conducted prior to algal bloom development. We collected ADCP data in May separately with UAV monitoring conducted in August. During the ADCP measurement campaign, the ADCP device platform was connected to one side of the boat. We use the Sontek RiverSurveyor M9 ADCP, whose spatial position was collected with a differential global positioning system (DGPS).

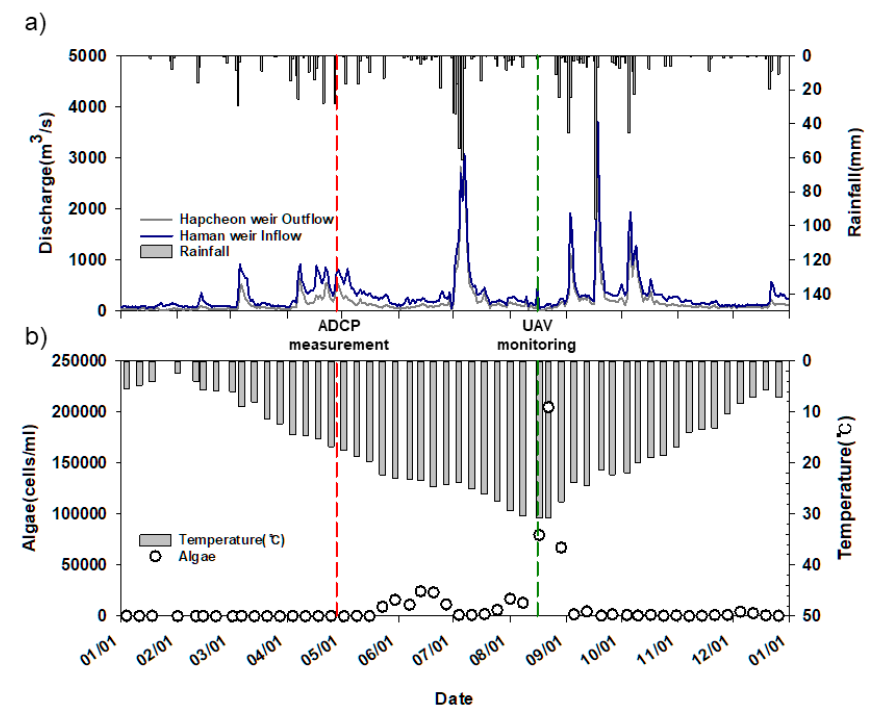

Figure 2. In situ conditions during the ADCP measurement and UAV monitoring campaigns from the various perspectives of (a) streamflow discharge and rainfall (at the outflow of Hapcheon weir and inflow of Haman weir) and (b) temperature and algal concentration in 2016.

\subsection{A Procedure to Evaluate the HAB Hotspots with ADCP Measurements}

Figure 3 shows the method of evaluating the HAB hotspots using the ADCP measurements of the flow velocity, depth, temperature, and backscatter of the target section. We note that the Geoda tool was utilized in this study to assess the spatial autocorrelation and perform the hot-spot analysis (https://spatial.uchicago.edu/geoda). The overall distribution of each variable was calculated through the spatial interpolation of the target section using the ADCP measurement data along the movement path. the distribution was then converted into a vector file (shapefile), where the index for predicting the HAB hotspots was calculated using the K-means cluster analysis (Equations (1)-(3)), followed by the hotspot analysis:

$$
\begin{gathered}
\mathrm{HAB}=\mathrm{fn}(\text { Temperature, Depth, Velocity, WCB }) \\
\mathrm{HAB} \propto \text { Temperature, WCB }, \frac{1}{\text { Depth }}, \frac{1}{\text { Velocity }} \\
\mathrm{HAB}=0.25\left(\mathrm{z}_{\text {temperature }}+\mathrm{z} \frac{1}{\text { Depth }}+\mathrm{z} \frac{1}{\text { velocity }}+\mathrm{z}_{\text {Backscatter }}\right), \mathrm{z}=\frac{\mathrm{z}-\mathrm{z}_{\text {min }}}{\mathrm{z}_{\max }-\mathrm{z}_{\min }}
\end{gathered}
$$




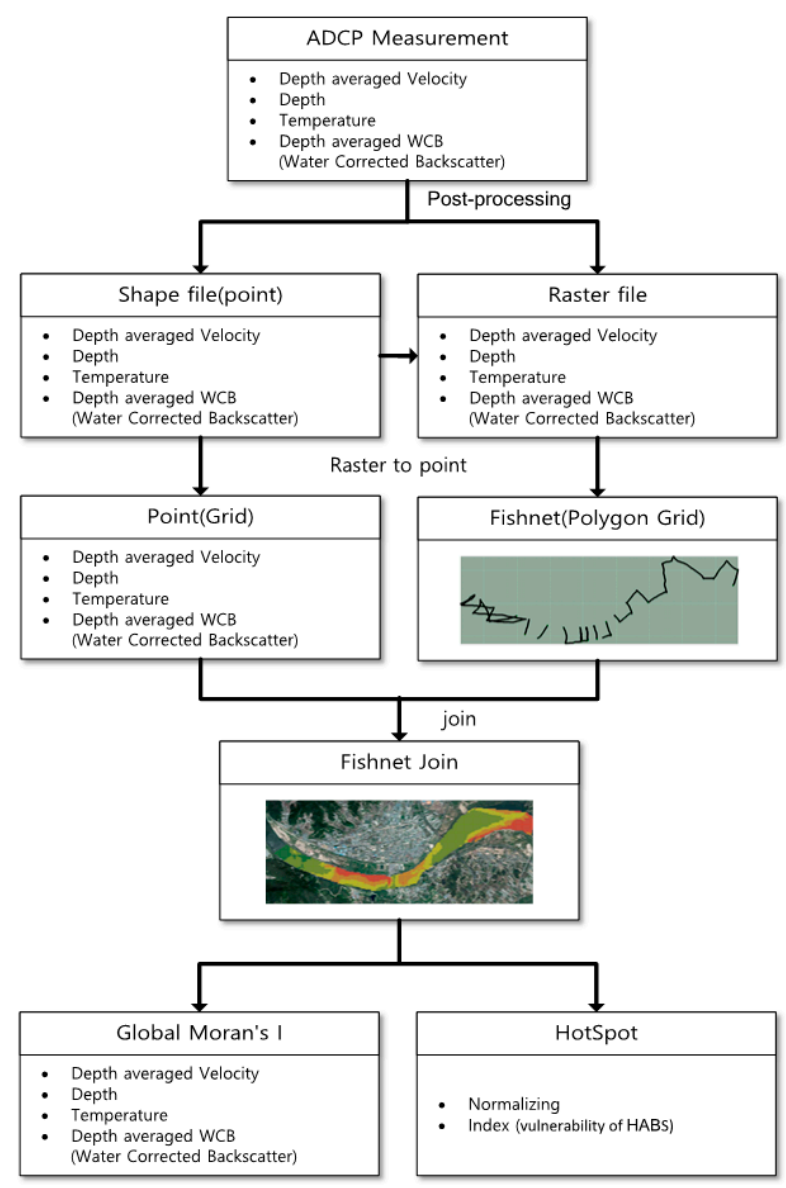

Figure 3. A step-by-step procedure to derive HAB-prone regions based solely on ADCP measurement, with the application of statistical approaches for the spatial autocorrelation and hot-spot analysis tools.

\subsection{Processing ADCP Backscatter}

ADCPs mounted to boats were operated in various riverine areas to measure detailed flow velocity profiles and bathymetry in terms of the returned ultrasonic waves backscattered from suspended materials and the riverbed, respectively. In addition to temperature, ADCPs provide velocity and bathymetry information without requiring further data processing. However, backscatter data should be processed to yield the proper output [31,32]. In this study, backscatter values measured with an $\mathrm{ADCP}$ were assumed to be a surrogate parameter for evaluating HAB-prone regions based on the principle that the amount of suspended matter in a water body can be relevant to the flourishment of algae. Decayed sonic signals should be compensated for in the raw observed backscattered data due to absorption by water and beam spreading along the beam path. Equation (4) shows the conventional sonar algorithm adapted to correct for the measured backscatter [43]:

$$
\mathrm{WCB}(\text { Water Corrected Backscatter })=\mathrm{MB}+20 \log _{10}(\psi \mathrm{r})+2 \mathrm{r} \alpha_{\mathrm{w}}
$$

where WCB is the corrected backscatter for which beam spreading and absorption by water were corrected and MB is the measured backscatter. Specifically, the second term, i.e., $20 \log _{10}(\psi r)$, represents the correction of the backscatter according to the distance and the third term, i.e., $2 \mathrm{r} \alpha_{\mathrm{w}}$, is the correction for absorption by water. We note that Equation (4) does not correct for absorption and scatter due to suspended matter. The ADCP data consist of cells (e.g., a $2 \mathrm{~cm}$ rectangle) in the cross-section, enabling us to obtain a backscatter and velocity value. Consequently, three-dimensional profiling of the backscatter is possible along the moving track of the ADCP. In this study, however, the profiled 
backscatters were averaged in the depth direction to set up an analogous dimension with temperature and bathymetry. A similar averaging procedure was applied for the velocity profile measurements.

\subsection{Spatial Autocorrelation Analysis}

Spatial autocorrelation exists when the characteristics of adjacent spatial data are similar to each other [44]. Areas that are close to each other as spatially distributed data have similar values, which can be defined as having spatial autocorrelation. For instance, there are local patterns in the water temperature, indicating that a certain portion of the area can be grouped according to their degree of temperature, which is identical for the velocity, bathymetry, and backscatter. Moran's I is a well-known measure or index in geostatistical fields used to judge the presence of spatial autocorrelation for collected ADCP data [45]. Moran's I computes the autocorrelation based on the spatial position and attributes of point measurements introduced in Equation (5). Prior to detecting HAB-prone regions based on clustering or hot spot analysis, we must clarify that spatial data are regionalized with similar neighborhood correlations. Otherwise, spatial data are scattered, such that further clustering or hot-spot analysis becomes meaningless. Spatial autocorrelation analysis has been traditionally used to investigate regional connections or relationships between spatial distributions $[44,46]$ defined spatial autocorrelation as a phenomenon in which the similarity of the values of objects increases with the increasing similarity of the locations of the objects in a space. This study applied Moran's I method, based on the procedures reported in [44], as an index to determine whether spatial autocorrelation exists inside individual parameters obtained by the ADCP. If so, those data can be readily utilized to derive the HAB-prone regions with the following steps. If Moran's I is close to 1, this indicates a high similarity for spatially adjacent measurement data. If Moran's I is close to -1 , the similarity among adjacent measurement data is low. The equation for Moran's I is as follows (Equation (5)):

$$
I_{\text {global }}=\frac{N \sum_{i=1}^{n} \sum_{j=1}^{n} W_{i j}\left(X_{i}-\bar{X}\right)\left(X_{j}-\bar{X}\right)}{\left(\sum_{i=1}^{n} \sum_{j=1}^{n} W_{i j}\right) \sum_{i=1}^{n}\left(X_{i}-\bar{X}\right)^{2}}
$$

show authors did the figure. Where $N$ is the number of data in the target section, $\bar{X}$ is the mean, $X_{i}$ is the attribute value of position $i, X_{j}$ is the attribute value of position $j$, and $W_{i j}$ is the weight.

As Moran's I defined in Equation (5) assesses a single global spatial autocorrelation index to represent the overall similarity between the given data and area, it does not encompass the local variations in spatial autocorrelation. In this regard, the local index of spatial association (LISA) was proposed by [36] to provide information on the spatial pattern of autocorrelation in the target section. Thus, to analyze the spatial autocorrelation pattern of the target section, the local spatial autocorrelation can be analyzed as follows [36] (Equations (6) and (7)):

$$
\begin{gathered}
I_{\text {local }}=\left(\left(X_{i}-\bar{X}\right) / s_{i}^{2}\right) \sum_{j=1}^{n} W_{i, j}\left(X_{j}-\bar{X}\right), j \neq I \\
s_{i}^{2}=\frac{\sum_{j=1, j \neq i}^{n}\left(X_{i}-\bar{X}\right)^{2}}{(n-1)}-\bar{X}^{2}
\end{gathered}
$$

\subsection{Hot-Spot Analysis}

Hotspot analysis is a method for analyzing spatially clustered distributions. For hot-spot analysis, this study applied the K-means algorithm, which is a well-known unsupervised learning algorithm that divides the given data into k clusters, where the clusters are derived in such a manner as to minimize 
the distance from the center of each cluster to each sample point [33]. By specifying the number of clusters, the given data can be classified into k clusters that yield similar characteristics. The K-means algorithm, in particular, is straightforward because it does not require training with respect to the data patterns and structures. Although this method collocated an ambiguity in the selection of the number of $\mathrm{k}$ clusters, it is the most representative algorithm for classification through unsupervised learning that can predict and classify data that do not have actual result values.

Another representative method used for hotspot analysis in this study is Getis-ord $\mathrm{G}_{\mathrm{i}}^{*}[34,35]$. As a classification method, Getis-ord $G_{i}^{*}$ can analyze spatially clustered locations based on the z-score. This method is a high/low clustering statistic that can be interpreted within the context of the null hypothesis based on the absence of spatial clustering of featured values. The interpretation of the Getis-Ord statistic is as follows: a value larger than the mean (or a positive value for a standardized z-score) suggests a high-high cluster or hot spot, a value smaller than the mean (or a negative z-score) indicates a low-low cluster or cold spot. The Getis-Ord approach does not consider spatial outliers. We will not discuss the detailed underlying principles of the function of the Getis-Ord $\mathrm{G}^{*}$ equation $[34,35]$. The equation for the Getis-ord $G_{i}^{*}$ method, which can be used to analyze hot and cold spots, is as follows (Equations (8)-(10)):

$$
\begin{gathered}
G_{i}^{*}=\frac{\sum_{j=1}^{n} W_{i, j} X_{j}-\bar{X} \sum_{j=1}^{n} W_{i, j}}{S \sqrt{\frac{\left[\sum_{j=1}^{n} w_{i, j}^{2}-\left(\sum_{j=1}^{n} W_{i, j}\right)^{2}\right]}{n-1}}} \\
\bar{X}=\frac{\sum_{j=1}^{n} X_{j}}{n} \\
S=\sqrt{\frac{\sum_{j=1}^{n} X_{j}^{2}}{n}-(\bar{X})^{2}}
\end{gathered}
$$

Consequently, we analyzed the existence of spatial autocorrelation in each ADCP measurement using Moran's I, which can yield the global spatial autocorrelation. For local spatial autocorrelation analysis, we analyzed whether the measurement data have spatial correlations and investigated the spatial autocorrelation patterns by examining the clustering characteristics of each dataset through LISA. Furthermore, the HAB hotspots were analyzed through hotspot analysis based on a K-means cluster analysis and HAB hotspot index using each measurement result.

\section{Results and Discussion}

\subsection{ADCP Measurement Results (Flow Velocity, Depth, Temperature, and Backscatter)}

ADCP data were collected, as illustrated in Figure 1, where spatial interpolation was performed to individually represent the flow velocity, depth, temperature, and backscatter in the form of the maps shown in Figure 4. The measurements were performed immediately after the rainfall that occurred on 28 April 2016. The temperature was the highest near the left bank, i.e., approximately $1.5 \mathrm{~km}$ downstream from the upstream area of the target section, and near the downstream segment of the target section. The water depth was the deepest near the Chilseo water treatment plant while the water depth was shallow near the left bank at the upstream segment of the target section and in the section where the width of the downstream segment widens. Furthermore, the mean flow velocity in the target section was approximately $0.25 \mathrm{~m} / \mathrm{s}$, where the flow velocity was low along both banks with shallow bathymetries. The backscatter was the highest at the downstream segment of the target section. The actual measurement results using the ADCP demonstrated notable spatial patterns along the study area and locally clustered regional distinctions. For quantitative evaluation of such a trend, 
the aforementioned spatial autocorrelation analysis of the target section was performed for each parametric map in terms of the Moran scatter plot with the global Moran's I and LISA.

(a)

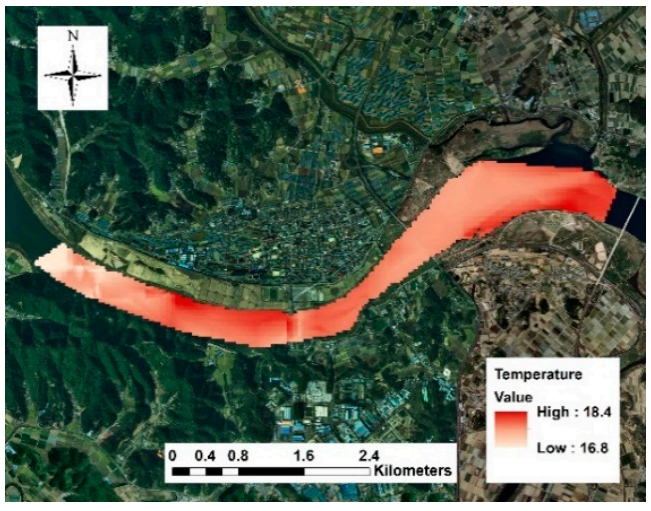

(c)

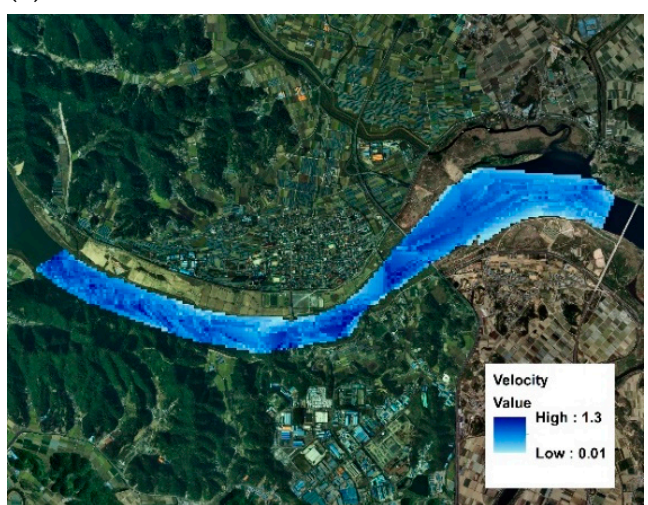

(b)

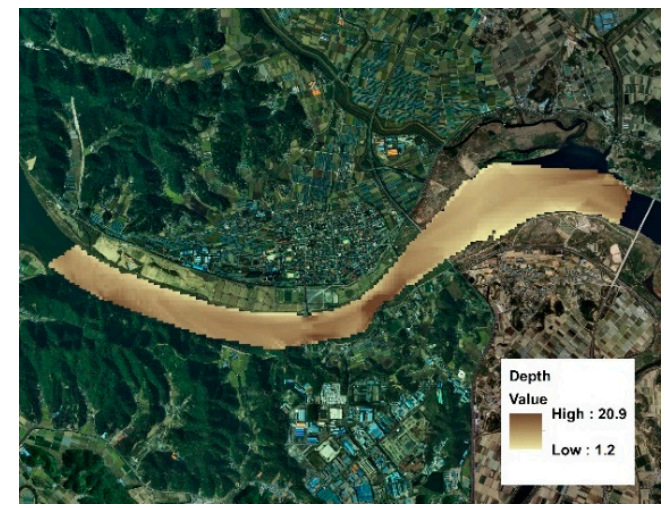

(d)

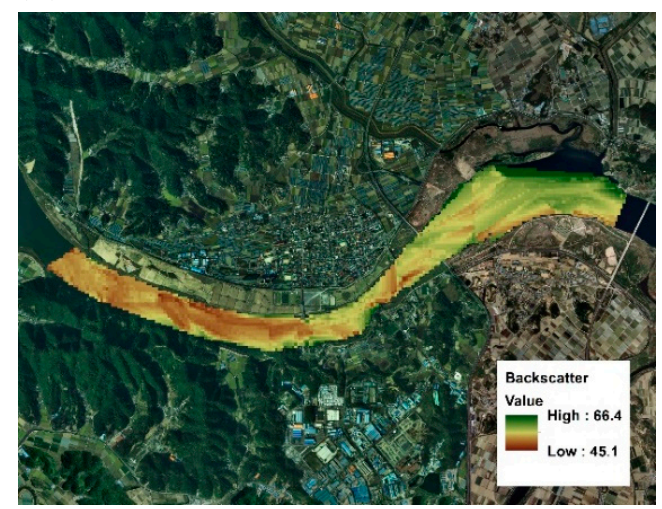

Figure 4. Hydro-morphodynamic parameters collected by the ADCP: (a) water surface temperature, (b) bathymetry, (c) depth-averaged velocity, and (d) backscatter.

\subsection{Spatial Autocorrelation}

Spatial autocorrelation analysis was conducted to quantitatively determine the existence of spatial correlations inside of each parametric map in Figure 4. First, the Moran scatter plot was derived for the ADCP parameters in Figure 5. The Moran scatter plot denotes spatial autocorrelation in an exploratory manor, enabling us to account for how an observed value is similar to its neighborhood observations, where the horizontal axis indicates the observed value and the corresponding vertical axis results in a weighted average within the spatial lag (neighborhood size). Moreover, the slope of regressing the Moran scatter plot indicates the global Moran's I, which characterizes the overall rate of spatial autocorrelation for the entire dataset with a single value. For example, a value of 1.0 for Moran's I indicates a perfect correlation with its neighborhood. Table 1 lists the resulting global Moran's I for each ADCP parameter. The Moran's I for temperature, bathymetry, and backscatter indicated very high spatial correlations greater than 0.9 , which ultimately led to the fact that these three parameters contain prominent local trends, enabling them to be reasonably grouped for further hotspot analysis. Despite the fact that the velocity was relatively low, i.e., approximately 0.75 , noticeably deviated from the other value, the local velocity can change more dynamically compared with the other parameters. However, even the z-score of the velocity reached 136.7, which is similar to the other parameters, indicating that there is still a possibility to formulate clusters with adjacent areas. More specifically, the Moran scatter plot for the bathymetry included certain identifiable outliers that bathymetry can change both locally and substantially. Although the slope is similar between the temperature and 
backscatter (i.e., sediment), the Moran scatterplot of the backscatter reveals that it was more dispersed than temperature, which indicates that a local uncorrelated region for sediment distribution can exist. Collectively, the global Moran's analysis of the ADCP parameters outlined a suitable spatial correlation readily useful for further clustering them from the local area to the area toward the HAB-prone region.

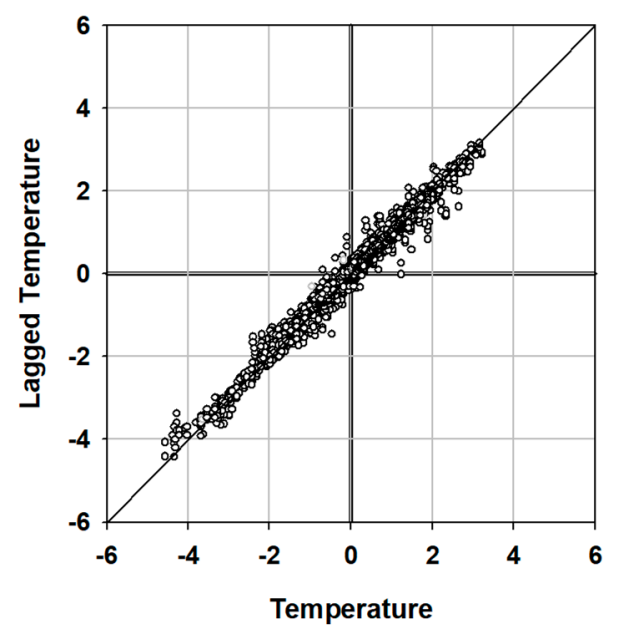

(a)

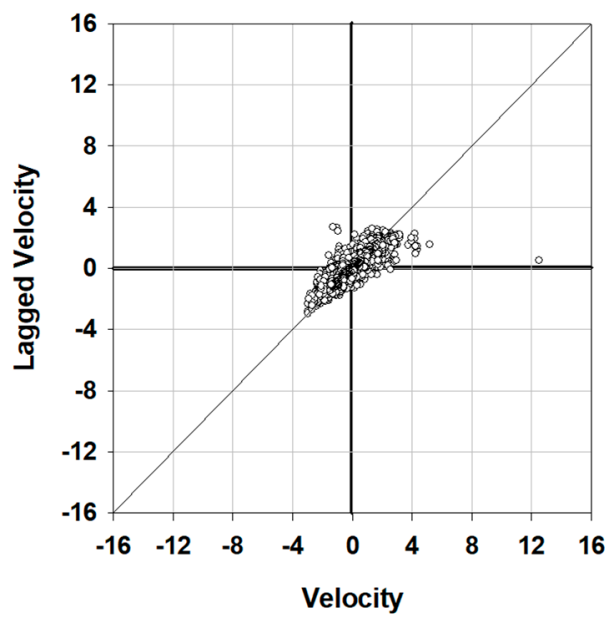

(c)

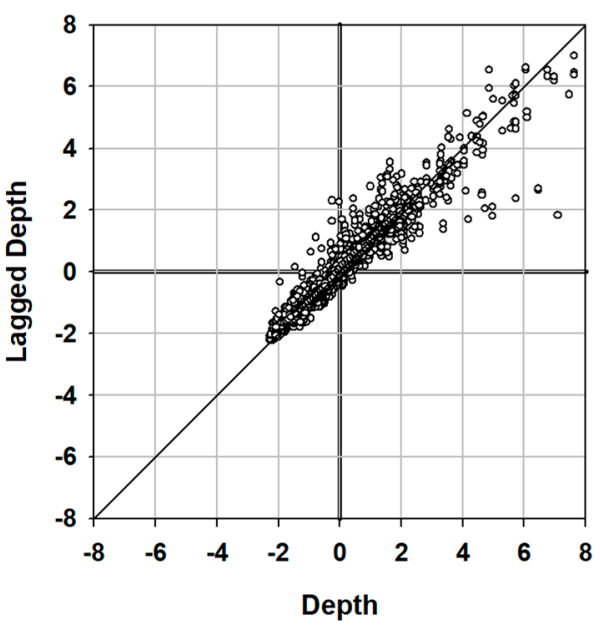

(b)

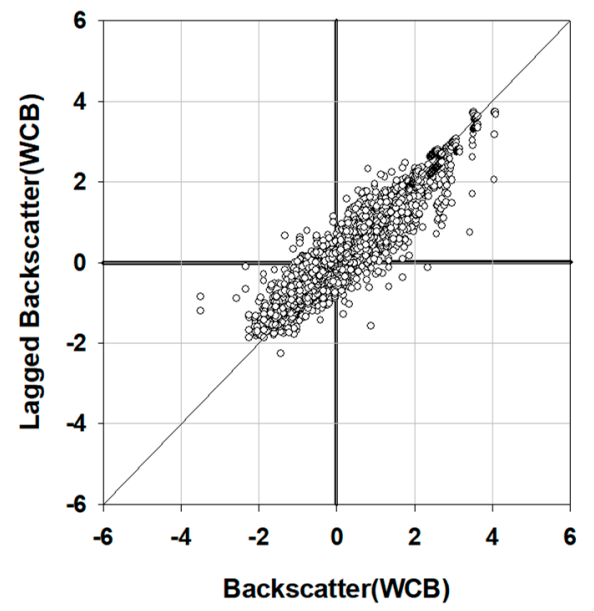

(d)

Figure 5. Moran scatter plots to identify the spatial autocorrelation for various ADCP-based observations: (a) temperature, (b) bathymetry, (c) velocity, and (d) backscatter.

Table 1. Global Moran's I and its statistics applied for each parametric map produced from the ADCP measurements.

\begin{tabular}{cccc}
\hline Variables & Moran's I & $\boldsymbol{p}$-Value & z-Score \\
\hline Temperature & 0.979 & 0.000116 & 174.2346 \\
\hline Depth & 0.933 & 0.000116 & 169.1159 \\
\hline Velocity & 0.757 & 0.000116 & 136.7478 \\
\hline Backscatter & 0.905 & 0.000116 & 162.4183 \\
\hline
\end{tabular}

In addition to the Global Moran's I, LISA is a global index for analyzing the spatial autocorrelation with one value [36]. LISA was performed to analyze the local pattern of spatial autocorrelation in the study area. LISA decomposes the global indicator of Moran's I into the contribution of each local observation, which, in turn, leads to spatial mapping of the local autocorrelation index. Consequently, LISA can be referred to as the localized Moran's I, which has been used to assess the influence that 
individual locations have on the magnitude of the global statistic and identify likely outliers using the Moran scatter plot. In this context, substantiating the trends in a spatial manor is better to ensure local autocorrelation in more detail, rather than Moran's I and a scatterplot. Among the various degrees used to represent LISA, this study simplified the regions into four categories: HH (high values are surrounded by high values), LL (low values are surrounded by low values), HL (high values are surrounded by low values), and LH (low values are surrounded by high values) This simplified classification was intended to synthetically encapsulate the overall spatial difference affecting the algal blooms and identify their localized presence for the further use of hot-spot analysis.

Figure 6 shows the localized spatial autocorrelation driven by the LISA analysis regarding the ADCP measurements, which yields a distinct presence of relatively high and low regions for all four parameters. We note that black-colored vacant areas appeared adjacent to the HH and LL regions, indicating that those regions are not statistically significant and are therefore unable to address local spatial autocorrelation used for further hot-spot analysis.

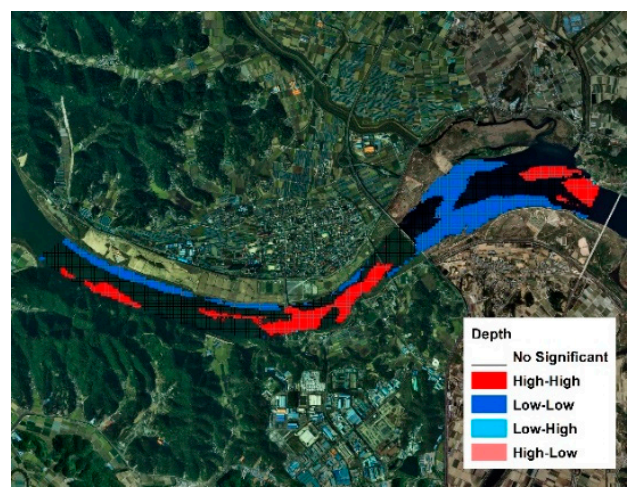

(a)

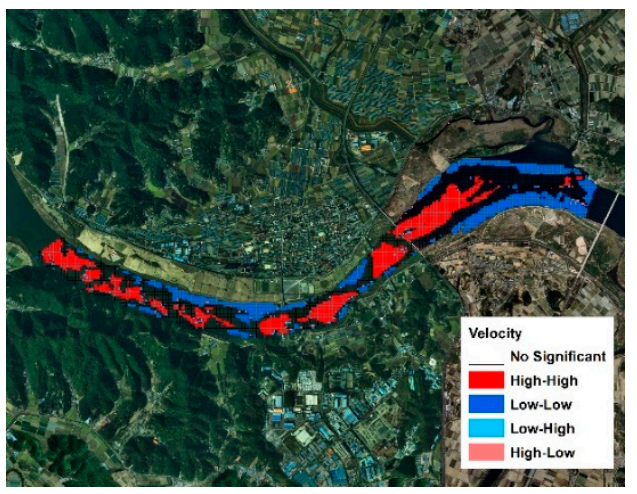

(c)

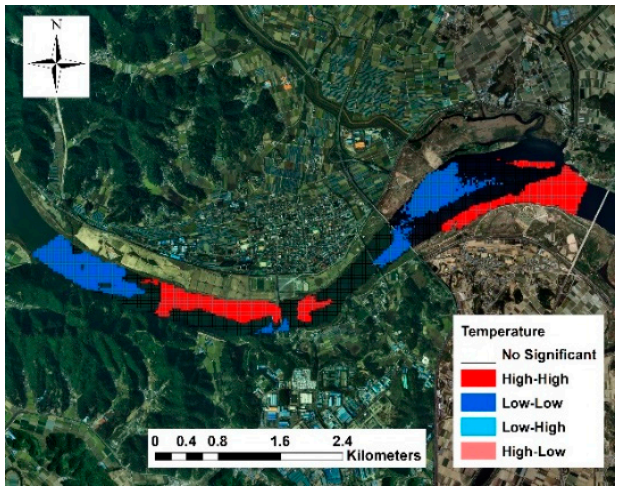

(b)

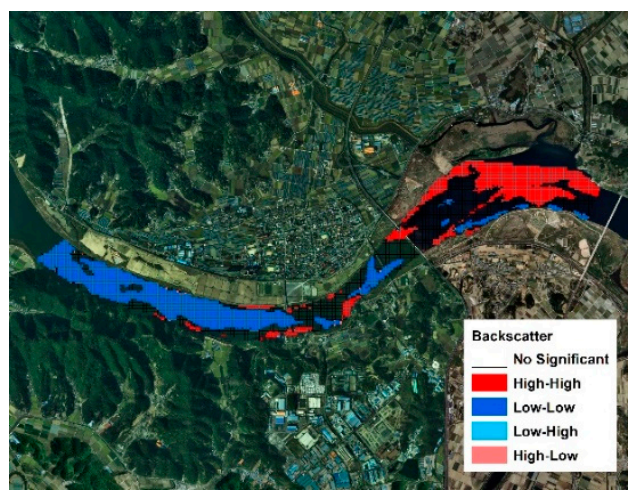

(d)

Figure 6. Spatial correlation maps applying the LISA method to the ADCP measurements, where high-high (red) and low-low (blue) regions for each parameter are spatially represented to statistically demonstrate the presence of local spatial trends: (a) surface temperature, (b) bathymetry, (c) depth-averaged velocity, and (d) backscatter (suspended matter).

Physically, this black-colored area may be related to the mixing region induced by tributary flow, especially for the temperature and sediment distribution. For the temperature, a low-temperature area (LL) and a high temperature area $(\mathrm{HH})$ appeared in turn along with the downstream direction. For the morphologic characteristics (i.e., bathymetry), low depth areas (LL) were positioned along the left bank in the initial section while a cluster of LL areas appeared in the most downstream area of the target section. For the flow velocity, LL areas appeared along both banks of the river, similar to the flow velocity distribution of the actual rivers while an $\mathrm{HH}$ area formed in the center of the channel. Furthermore, with respect to the backscatter (i.e., suspended matter), the upstream segment of the 
study area was an LL area while the downstream segment was an HH area. The LISA analysis results for each parameter revealed high temperature, low bathymetry, low velocity, and high backscatter areas with suspended matter in the water body, which can potentially be susceptible to harmful algal blooms, as denoted in Equation(1). This assembled information becomes the underlying cause that plays a crucial role in algal bloom development, from which hot-spots can be more or less interactive.

\subsection{Analysis Results of the HAB Hotspots}

As mentioned before, this study adapted two methods for hot-spot analysis to identify the HAB-prone regions, i.e., K-means clustering and Getis Ord $\mathrm{G}^{*}$, which yield the coarse classification of HAB-prone regions as hot-spot versus cold-spot areas. Figure 7 shows the results that can be visually inspected for both approaches collectively using the temperature, depth, flow velocity, and backscatter. These methods ensured that the parameters locally demonstrated spatial autocorrelations, such that they are readily applicable for hot-spot analysis. To expedite the quantitative estimation of the degree of hot spots (i.e., hot or cold spot), the K-means clustering method adapted the number of clusters simply as 2 (i.e., $\mathrm{k}$ of the K-means cluster), which enables us to extract the HAB hotspot or not, as represented in Figure 7a. The results indicate red-colored high areas as hot-spots, commensurate with HAB-prone regions that satisfy high temperature and backscatter, and low bathymetry and velocity based on the required conditions for algae, as described in Equation (1). The subtle texture of hot-spots corresponding to algal blooms formed along both banks of the river, where low bathymetry and velocity were dominant. The right bank in the downstream vicinity of tributary intrusion did not display a high hot-spot (rather a cold-spot), which was mainly attributed to the lower temperature and sediment flow originating from the tributary, i.e., Nam River. In the middle of the downstream segment at the beginning of a meander, however, the effect of the meander and narrowed width increased the flow velocity, yielding a concurrent increase in the bathymetry. Consequently, the hot-spot substantially disappeared in this section. For this reason, our analysis revealed that there are no concerns with respect to algal blooms in this part of the study area. Along with the downstream area where there is a gradual expansion of the river width, the velocity decreased and the bathymetry had a shallower morphology, such that the hot-spot of the HAB-prone region increasingly became more pronounced again.

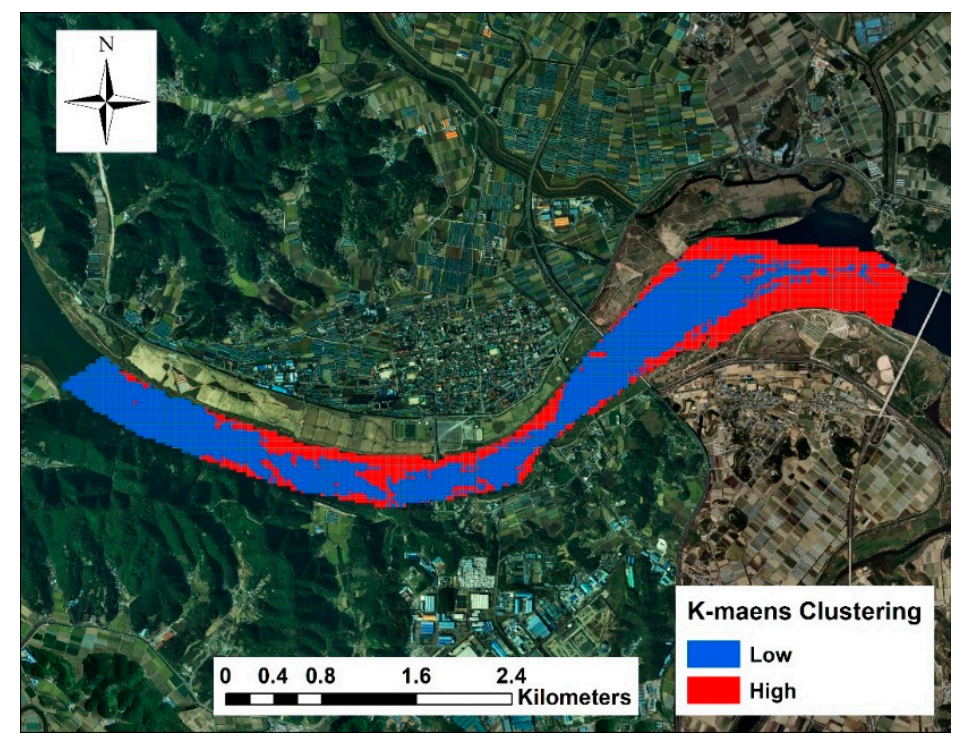

(a)

Figure 7. Cont. 


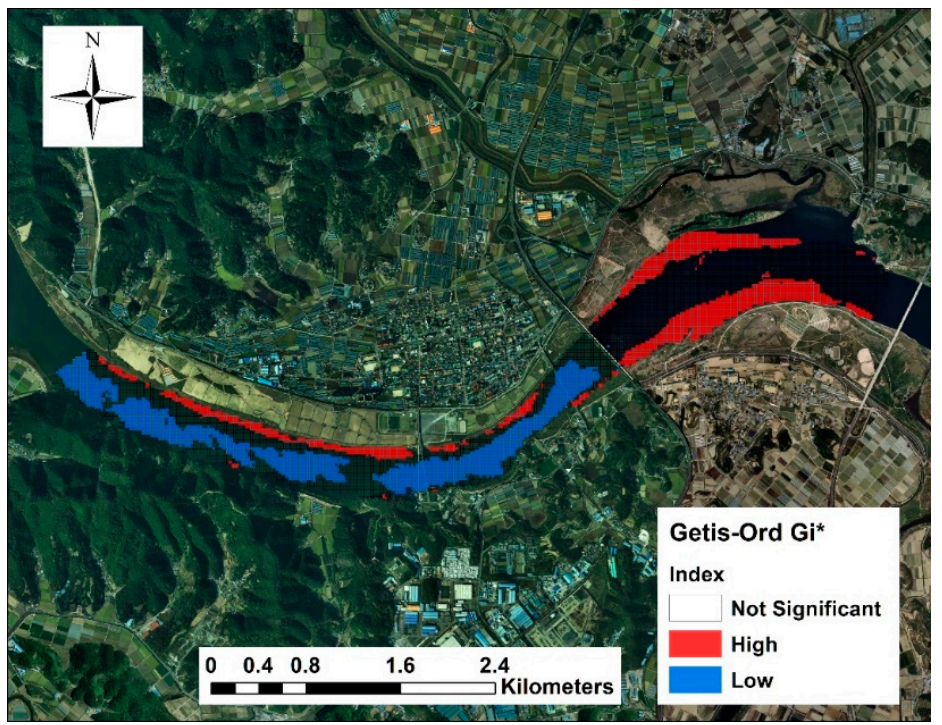

(b)

Figure 7. HAB-prone regions based on hot-spot analysis in the downstream vicinity of the Nakdong and Nam rivers confluence: (a) K-means clustering method and (b) Getis-Ord G* method. The red-colored areas correspond to HAB-prone regions, blue-colored areas indicate a region with a reduced likelihood of an $\mathrm{HAB}$, and the remaining black-colored areas are not subject to any category.

Figure $7 \mathrm{~b}$ demonstrates the hot-spot analysis using the Getis-Ord $\mathrm{G}^{*}$ method, as a second approach, which was, to various degrees, analogous to that of the K-means clustering method shown in Figure 7a. In comparison with the K-means clustering, the Getis-Ord $\mathrm{G}^{*}$ method showed two major differing outcomes. First, the Getis-Ord $G^{*}$ method additionally allocated a black-colored area that is not subject to any high or low category that appeared in the K-means clustering method. In the meantime, the characteristics of this area can be susceptible to both hot and cold regions, suggesting that the algal bloom initiated in the red-colored hot-spot region, such that it more likely pertains to evolution toward this black-colored middle region rather than a cold spot with a blue color. For example, the region immediately downstream of a main bridge (see Nakdong bridge in Figure 1) was mostly classified as a cold region with blue color, except for a very thin margin of the section of the hot-spot; there was no remarkable difference before and after Nakdong bridge. However, Getis-Ord $G^{*}$ distinctively divided these areas into cold spots before Nakdong bridge, with higher velocity and deeper bathymetry, as well as a black-colored middle region that will be relatively more vulnerable with additional algal blooms, although it is not yet a hot-spot. This result is consistent with the physical characteristics of this area, i.e., streamlining of the locations that accelerated the flow before Nakdong bridge because the meander and narrowed channel width would still maintain the momentum of the stream, particularly in the center of the channel after the bridge. Thus, this centered region is sufficiently mature enough to be characterized as a cold-region, as derived from the K-means clustering method.

Second, in the downstream vicinity of the confluence (significantly upstream of the study area), the Getis-Ord $G^{*}$ method revealed that the right side of the channel can be fully characterized as a cold spot that interacts with the tributary effect. We observed that the texture of the hot-spot in Figure 7a was not as likely as that shown in Figure $7 \mathrm{~b}$, where the K-means clustering yielded a sporadic and segmented hot-spot along the narrow right side of the channel. This difference may depend on the distance over which the impact of the tributary affected the downstream direction.

\subsection{Validation in Conjunction with UAV-Based Photographs}

Together with recent advances in UAV monitoring in riverine environments, the monitoring of HABs have become more immediately relevant than other methods, which ensures that the outcomes 
of this study can be proposed as a comprehensive and quick-and-simple method to ultimately forecast HAB-prone regions. This contemporary type of UAV survey in various riverine environments has become increasingly popular because of its low cost and simple deployment [47]. Most civil drones are equipped with digital cameras with continuously increasing resolution and positioning accuracy, such that they have become reliable substitutes for conventional expensive aerial photography to visually inspect the spatial trend of HABs over time. The UAV-based monitoring campaign in this study was conducted during August 2016, after HABs had been reported annually in this region every summer, which was a sufficiently long period from the ADCP measurement campaign in June, when algal blooms had not yet proliferated. During the three month interval between the prediction and validation by ADCP and UAV, respectively, there were no distinctive changes in terms of the flow and morphologic regime, except for several rainfall events. Based on these factors, we attempted to validate the results from the hot-spot analysis using ADCP in Figure 8 in conjunction with the actual $\mathrm{HAB}$ occurrence revealed by the UAV campaign for the given time interval.

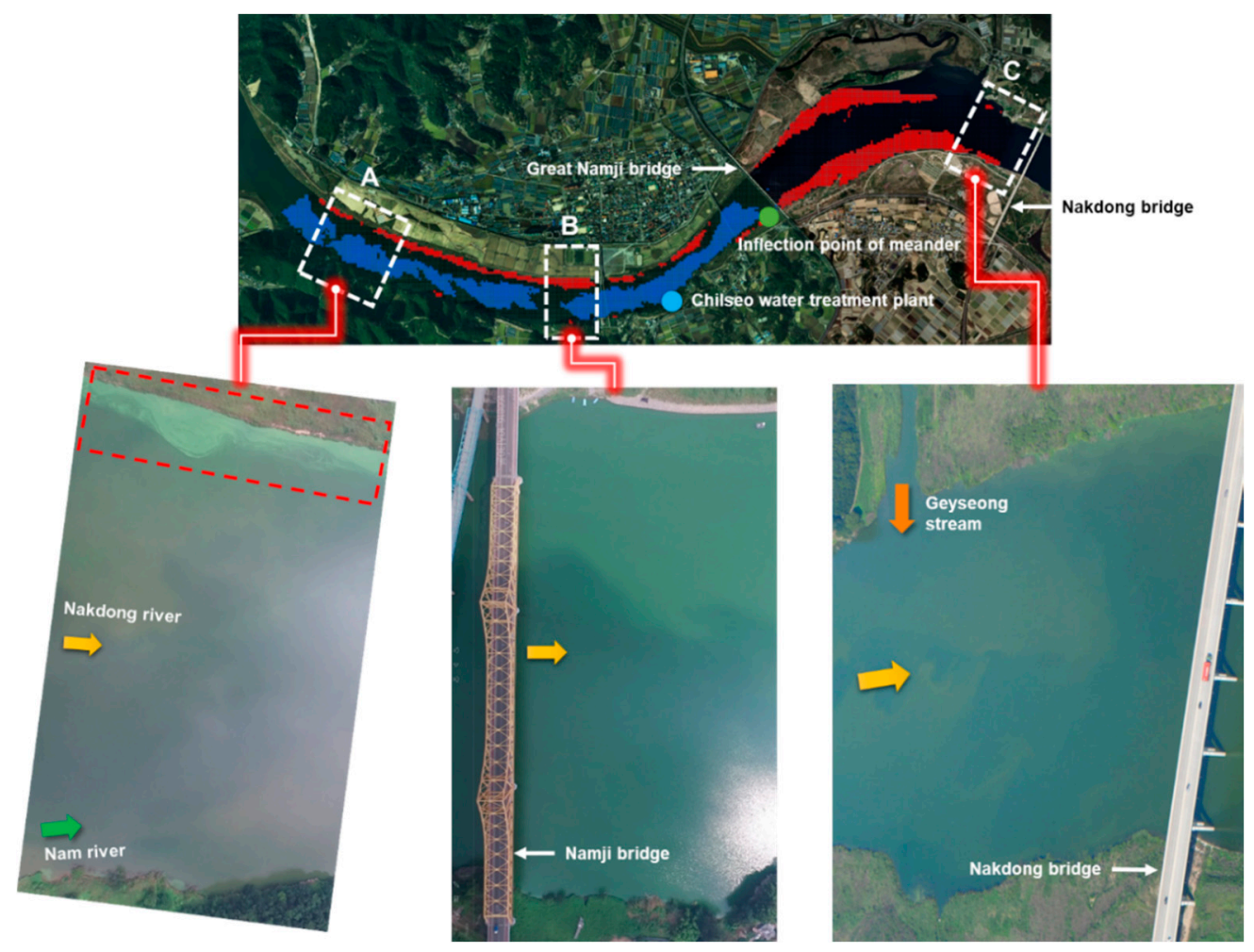

Figure 8. A comparison between the HAB-prone regions and UAV-based photographs to visually inspect algal bloom occurrences, where the specified areas of A, B, and C were located at the upper, middle, lower regions of the study area to individually represent the impacts of confluence, meandering and adjacent water intake, and channel width expansion, respectively. These figures also show the location of Chilseo drinking water intake, as well as Nam River and Geyseong stream as tributaries located in the upstream and downstream reaches, respectively. Note that the HAB-prone regions were derived from a hot-spot analysis using Getis-Ord G* based solely on ADCP measurements, where the red-colored areas indicate areas susceptible to algal blooms.

To address this, Figure 8 shows the UAV-monitoring results during a period of HAB occurrence based on a series of aerial photographs. We used a commercial drone (Fathom IV, DJI) to acquire the photographs over a period of approximately half of a day. The photographed results ensured that the UAV survey can provide useful information to spatially identify the current status of the algal blooms. This UAV-based survey entailed a low-altitude flight of approximately $100 \mathrm{~m}$ with continuous image recordings and spatial resolution at the sub-centimeter scale. To facilitate comparisons and 
interpretation of the results, Figure 8 specifies the UAV monitoring areas by selecting three major local areas marked as $\mathrm{A}, \mathrm{B}$, and $\mathrm{C}$ above the HAB-prone regions based on the hot-spot analysis with Getis-Ord $G^{*}$. These specified areas, i.e., A, B, and C, were mostly located at the upper, middle, and lower regions of the study area to individually represent the impacts of the confluence, meandering and adjacent water intake, and channel width expansion, respectively.

More specifically, area A is located at the immediate downstream section of the Nam River confluence. The UAV monitoring results showed that HABs appeared only along the left bank in area A, which was highly similar to the hot-spot analysis based on the Getis-Ord G*method. Such a textured pattern was simultaneously maintained downstream, whereas there was no visual indication of an algal bloom along the right side margin of the channel corridor. This result can be attributed to the intrusion of the Nam River. Nevertheless, we suggest that the presence of a very small red spot, as well as a black-colored area on the right margin from the Getis-Ord G* results, should be viewed with caution, although these spots are not as prominent they are from the K-means clustering method results. This indicates that the right side of area A may also be susceptible and of concern for algal blooms when they expand due to worsening conditions, despite the fact that no current and imminent algal blooms were identified on the day of UAV monitoring.

Area B is the downstream section of Namji Bridge, where the Chilseo water treatment plant has been in operation for the last several decades downstream of the photographed section. A visual comparison between the UAV-monitored photograph and hot-spot analysis revealed similar patterns where algae bloomed on the left side of the channel and became more developed toward the center of the channel, as compared with area A. Therefore, the coverage of the bloom expanded downstream on this side. In contrast, there was still an absence of algal blooms on the right side of the channel, which inherited the characteristics of the blooms identified in area A. These results also correspond to the results of the hot-spot analysis, thereby validating that the proposed method based on ADCP data can predict algal blooms as revealed by on our identification of the HAB-prone region in area $\mathrm{B}$.

From this context, these findings can be extended to other practical applications as follows. In the absence of an HAB-prone area, as revealed by either the hot-spot analysis or UAV-monitoring at the beginning of the confluence, as observed in area $\mathrm{A}$, this pattern persisted on the right side of the channel along the downstream region almost until Nakdong Bridge, arriving near the inflection point of the meandering direction, as illustrated in Figure 8. This confirms that the contribution from the Nam River, in terms of suppressing HABs, persisted to the region where the tributary no longer has an influence, i.e., the completion of mixing. This is an important perspective when evaluating the safety of the drinking water intake located in the vicinity of area B (see Figure 8), where harmful microcystins residing in the blue-green algae can significantly threaten public drinking water intake systems. Given that the mega-cities surrounding the intake, such as Daegu and Busan, heavily rely on this specific drinking water intake, significant concerns have subsequently emerged after the continual occurrences of annual algal blooms in this river corridor with the completion of the four major river projects in 2012 [1,2]. Therefore, whether this water intake is be directly affected by HABs and the type of influence that intrusion from Nam River has on these HABs at this point are critical issues. Based on observations of the location of Chilseo intake, adjacent to area $\mathrm{B}$, we can observe that this location is out of the range of the HAB-prone area. The results from this study indicate that the algal bloom did not initiate in the area near the intake on the right side of the channel, rather it tended to initiate at the opposite side of the channel owing to the influence of Nam River. Collectively, the intake is able to maintain its quality due to Nam River, i.e., its quality is not maintained by Nakdong River with algal blooms; therefore, this station and its drinking water are safe until the outbreak of a significantly large algal bloom. The above results, therefore, also reveal the novelty of this study with the use of ADCPs, which can conveniently delineate whether certain critical areas, such as a water intake station, will be prone to HABs before the algae season. However, we note that once a very large algae outbreak (e.g., more than one million cells per liter) dominated all of the river channels, the intake was affected by harmful algae, as previously reported in the press. 
Finally, area $\mathrm{C}$ is located in the downstream region of Namji Bridge (Figure 8), which is characterized by an overall lower bathymetry, as compared with the upstream river corridor, a wide channel width, a slow flow velocity, a high water surface temperature, and a large backscatter. Thus, area $\mathrm{C}$ may be highly prone to algal blooms, whereas the area before Namji bridge is deeper and faster. However, due to the meandering feature, the right side of the channel in area $C$ was characterized by a slower and shallow flow regime, as shown in Figure 8, such that it may be prone to algal blooms. At this point, the positive influence from Nam River has disappeared before this area, which prevailed in areas $\mathrm{A}$ and $\mathrm{B}$, enabling the dilution of the main channel river; however, a small tributary, i.e., Gyeseng stream, enters the main channel in area $C$ from the left side of the channel near the apex of the meander (see Figure 8). This stream can be another source of nutrients or clean water from a small rural watershed, as well as the ability to play a role, to a certain degree, in expanding the channel geometry. Notable generic features are that the HAB-prone area derived from the ADCP data revealed that both the right and left sides of the channel yield hot-spots with red-colored areas (see area $C$ in Figure 8), whereas the center region was undetermined and more susceptible than the cold spot. Although the reason for the lack of HABs in this region is not clear and a number of factors are open to debate, we can suggest several hypotheses. For instance, the intrusion from Geyseong stream on the left side apex of the channel results in the temporary disappearance of the algal bloom. Overall, the algae emerged and proliferated in area $\mathrm{C}$ as a consequence of the aforementioned conditions, which were similarly confirmed by the UAV-based photograph. In terms of a visual inspection of the aerial photograph, however, the textured features of the algal bloom were more complex than predicted and, strictly speaking, the area in the photograph appeared slightly different in detail from that obtained with the hot-spot analysis. In reality, the algal bloom had already, to a certain extent, expanded from both banks toward the center of the channel, despite the fact that the spatial concentration of algal blooms was characterized by a lower degree. Although not clearly identified, the intrusion from Geyseong stream appears to have disturbed the spatial pattern and added a certain degree of complexity.

\subsection{Challenges and Lessons Learned}

This study predicted HAB hotspots using the temperature, depth, flow velocity, and backscatter data measured using an ADCP. Considering that most current studies on fluvial monitoring for algal blooms are locally limited, not cost-effective, laborious, and had to rely on remote sensing data, this method is consistent with remote sensing results, despite possible applicability constraints that do not include water quality data. ADCP has emerged throughout the last several decades and hydrometric communities and agencies around the world have accumulated ADCP measurements intended for various riverine applications, such as developing stage-discharge rating curves in diverse stages and flow regimes. Based on the availability of large ADCP datasets, this study proposed a practical technique to evaluate $\mathrm{HAB}$-prone regions with legacy $\mathrm{ADCP}$ data without further supplementary data collection, such as water quality. The comparative results with actual algal blooms revealed that the $\mathrm{ADCP}$ is feasible for the forecasting of HAB-prone regions with minimum preparedness and expense. In other words, we expect that this method will improve our capabilities of ultimately gaining a measure to forecast $\mathrm{HAB}$-prone regions based solely on ground-based monitoring.

However, there are certain issues that occurred during the development and validation of this procedure. Therefore, we provide a brief overview of the main challenges and lessons posed by environmental restrictions, tools, and data.

First, the proposed idea and methods for deriving undesirable HAB-prone areas was scrutinized using a case study of in situ ADCP measurements. For this reason, the present analysis and conclusions herein are based on a limited dataset; thus, the findings and validations remain preliminary. From this perspective, our outcomes should be regarded as indicative rather than confirmative. Further studies are therefore required to more precisely validate the proposed method. In contrast, the validation of the derived HAB-prone regions was conducted at a specified moment associated with the actual presence of HABs. Considering that the degree of severity of HABs can be interpreted differently over time and 
the analysis results in the synthetic plots reported in this study provide a specific case in which ADCP measurements preceded three months of subsequent development, current outcomes cannot separately account for different phases of algal blooms. As a consequence, we recommend more thorough studies for other temporal situations associated with algal blooms. Based on this study, however, we can stress that it is important to delineate areas susceptible to the initiation and development of algal blooms, which, for example, can occur in areas with the presence of a dead zone along the channel perimeter.

Second, this method can improve the flexibility of forecasting HAB-prone regions, allowing preemptive responses such as aeriation and chemical controls to substantial algal blooms, which enables us to develop elaborate countermeasures to mitigate the further proliferation of HABs by identifying where to begin and the isolation of that area. Hence, we can benefit from simple ADCP measurements with no other additional measurements. In general, seeds of algae locally distributed in a randomly segmented form particularly begin to grow in certain locations with highly suited preferable conditions. Therefore, this initial moment, at which the algae have not significantly bloomed, is the period when various bloom management methods should be performed, such as biomanipulation, soil drop, and physical elimination, enabling us to counteract and deteriorate algal blooms before their full proliferation overwhelms management capacities. This means that the abundance of legacy ADCP measurements, which numerous hydrometric agencies have accumulated over previous decades, can offer an effective preemptive approach to prevent massive algal blooms.

Third, given the acceptable agreement between the forecasted HAB-prone regions based on the ADCP measurements and the regions of actual algal blooms, the ADCP-based approach possibly allows for the precise identification or characterization of algal bloom, as opposed to the paucity of comprehensive datasets, including water quality. HAB-prone regions may form due to multiple reasons. Current methods cannot discern the type of algae due to the fact that different types of algae can prefer similar hydro- and morpho-dynamic riverine conditions. The addition of a water quality dataset, therefore, can place better constraints on the prediction of HAB-prone regions. However, we note that, in general, water quality data are only available at a limited fixed point instead of a large spatial coverage, as is the case for ADCPs. In the absence of such spatially distributed water quality data, the central theme of this study is the ability to fully utilize the valid benefits of ADCPs. Despite a decrease in the degree of accuracy and identification capacity type, ADCPs remain highly practical for forecasting HAB-prone regions.

Fourth, the majority of existing solutions for understanding the life cycles of algal growth have relied on sophisticated physically-based numerical simulations and calibrated point-based sporadic observations of agal blooms. In parallel, rapid advances in remote sensing technologies have shown significant potential for solving various research issues related to algal blooms, allowing the coverage of a riverine space with unprecedented efficacy. In contrast, this method relies on conventional ground-based direct measurements and subsequent data-driven modeling, such that this approach can be limited with respect to the accommodation of a broad range of flow environments and applications. Therefore, we suggest that the proposed method should be incorporated into a hybrid form with numerical models and remote sensing techniques.

\section{Conclusions}

The novelty of this study is the utilization of ADCP data to conjunctively identify HAB-prone regions. The proposed method aimed to develop a practical and rapid countermeasure, enabling a preemptive response to massive algal blooms, through which we can identify HAB-prone regions based on estimations of where harmful algae initiate and develop significant prior to the algal bloom season. We anticipate that this method can be used to mitigate ongoing environmental threats posed by unprecedented HABs, as well as for understanding algal blooms in freshwater systems. Considering relatively few studies have documented the performance and accuracy of using ADCP data to derive HAB-prone areas, this study highlights the usability of conventional acoustic methods and datasets, which have, to date, been massively accumulated by hydrometric communities. With a strategic 
combination of various ADCP measurement data to forecast HAB-prone regions, on the other hand, the method can be extended to encompass other emerging measurement techniques subsequently corroborated with measurements of water quality, which can provide a full description of the algal bloom process and their evolution. UAV surveys can offer useful complementary information on the monitoring of algal blooms, combined with emerging trends that will shape the best management practices to control HABs. We discussed the benefits and disadvantages of the proposed method, concluding that there is a need for further investigations to validate the feasibility of the proposed method by determining and optimizing all the available parameters. Tentatively, the Getis-Ord G* method yielded a better performance through comparative visual inspection, as compared with the photographs generated by UAV-based algal monitoring. Collectively, this method shows potential for forecasting HAB-prone regions, allowing preemptive responses before massive algal blooms, enabling the development of elaborate countermeasures to mitigate the further proliferation of HABs by identifying areas for isolation. We anticipate that this method can be used to mitigate ongoing environmental threats posed by unprecedented harmful algal blooms, as well as for understanding the formation and evolution of algal blooms in freshwater systems. These tools were assembled with the intent to aid and facilitate the forecasting HABs, followed by the application of measures to mitigate HABs and assess their degree. This approach can be readily applied by engineering or field operators.

Author Contributions: Conceptualization, D.K. and Y.D.K.; methodology, G.S. and S.K.; software, G.S.; validation, G.S.; formal analysis, S.K.; investigation, G.S. and D.K.; resources, Y.D.K.; data curation, S.L.; writing-original draft preparation, G.S.; writing-review and editing, D.K., S.K. and Y.D.K.; visualization, G.S.; supervision, D.K., S.L. and Y.D.K.; project administration, Y.D.K.; funding acquisition, Y.D.K. and S.L. All authors have read and agreed to the published version of the manuscript.

Funding: This research was funded by Korea Agency for Infrastructure Technology Advancement (KAIA) grant number 20DPIW-C153746-02.

Acknowledgments: The authors gratefully acknowledge the field work conducted by graduate students of Changwon National University, Dankook University, and Inje Univeristy.

Conflicts of Interest: The authors declare no conflict of interest.

\section{References}

1. Lah, T.J.; Park, Y.; Cho, Y.J. The four major rivers restoration project of South Korea: An assessment of its process, program, and political dimensions. J. Environ. Dev. 2015, 24, 375-394. [CrossRef]

2. Srivastava, A.; Ahn, C.-Y.; Asthana, R.K.; Lee, H.-G.; Oh, H.-M. Status, alert system, and prediction of cyanobacterial bloom in South Korea. Biomed Res. Int. 2015, 2015, 584696. [CrossRef] [PubMed]

3. Paerl, H.W.; Otten, T.G. Harmful cyanobacterial blooms: Causes, consequences, and controls. Microb. Ecol. 2013, 65, 995-1010. [CrossRef] [PubMed]

4. Brooks, B.W.; Lazorchak, J.M.; Howard, M.D.A.; Johnson, M.V.; Morton, S.L.; Perkins, D.A.K.; Reavie, E.D.; Scott, G.I.; Smith, S.A.; Steevens, J.A. Are harmful algal blooms becoming the greatest inland water quality threat to public health and aquatic ecosystems? Environ. Toxicol. Chem. 2016, 35, 6-13. [CrossRef]

5. Loza, V.; Perona, E.; Mateo, P. Specific responses to nitrogen and phosphorus enrichment in cyanobacteria: Factors influencing changes in species dominance along eutrophic gradients. Water Res. 2014, 48, 622-631. [CrossRef]

6. Paerl, H.W.; Xu, H.; McCarthy, M.J.; Zhu, G.; Qin, B.; Li, Y.; Gardner, W.S. Controlling harmful cyanobacterial blooms in a hyper-eutrophic lake (Lake Taihu, China): The need for a dual nutrient (N \& P) management strategy. Water Res. 2011, 45, 1973-1983.

7. Elliott, J.A. Is the future blue-green? A review of the current model predictions of how climate change could affect pelagic freshwater cyanobacteria. Water Res. 2012, 46, 1364-1371. [CrossRef]

8. Zhang, H.; Chen, R.; Li, F.; Chen, L. Effect of flow rate on environmental variables and phytoplankton dynamics: Results from field enclosures. Chin. J. Oceanol. Limnol. 2015, 33, 430-438. [CrossRef]

9. Paerl, H.W.; Huisman, J. Blooms like it hot. Science 2008, 320, 57-58. [CrossRef]

10. Cao, J.; Chu, Z.; Du, Y.; Hou, Z.; Wang, S. Phytoplankton dynamics and their relationship with environmental variables of Lake Poyang. Hydrol. Res. 2016, 47, 249-260. [CrossRef] 
11. Cho, S.; Lim, B.; Jung, J.; Kim, S.; Chae, H.; Park, J.; Park, S.; Park, J.K. Factors affecting algal blooms in a man-made lake and prediction using an artificial neural network. Measurement 2014, 53, 224-233. [CrossRef]

12. Kim, J.; Lee, T.; Seo, D. Algal bloom prediction of the lower Han River, Korea using the EFDC hydrodynamic and water quality model. Ecol. Model. 2017, 366, 27-36. [CrossRef]

13. Kim, H.G.; Hong, S.; Jeong, K.-S.; Kim, D.-K.; Joo, G.-J. Determination of sensitive variables regardless of hydrological alteration in artificial neural network model of chlorophyll a: Case study of Nakdong River. Ecol. Modell. 2019, 398, 67-76. [CrossRef]

14. Park, J.; Wang, D.; Lee, W.H. Evaluation of weir construction on water quality related to algal blooms in the Nakdong River. Environ. Earth Sci. 2018, 77, 408. [CrossRef]

15. Van der Merwe, D.; Price, K.P. Harmful algal bloom characterization at ultra-high spatial and temporal resolution using small unmanned aircraft systems. Toxins 2015, 7, 1065-1078. [CrossRef] [PubMed]

16. Park, Y.; Pyo, J.; Kwon, Y.S.; Cha, Y.; Lee, H.; Kang, T.; Cho, K.H. Evaluating physico-chemical influences on cyanobacterial blooms using hyperspectral images in inland water, Korea. Water Res. 2017, 126, 319-328. [CrossRef]

17. Kislik, C.; Dronova, I.; Kelly, M. UAVs in support of algal bloom research: A review of current applications and future opportunities. J. Drones 2018, 2, 35. [CrossRef]

18. Lekki, J.; Anderson, R.; Avouris, D.; Becker, R.; Churnside, J.; Cline, M.; Demers, J.; Leshkevich, G.; Liou, L.; Luvall, J. Airborne Hyperspectral Sensing of Monitoring Harmful Algal Blooms in the Great Lakes Region: System Calibration and Validation; NASA/TM-2017-219071; NASA: Cleveland, OH, USA, 2017.

19. Lekki, J.; Ruberg, S.; Binding, C.; Anderson, R.; Vander Woude, A. Airborne hyperspectral and satellite imaging of harmful algal blooms in the Great Lakes Region: Successes in sensing algal blooms. J. Great Lakes Res. 2019, 45, 405-412. [CrossRef]

20. Pyo, J.C.; Ligaray, M.; Kwon, Y.S.; Ahn, M.-H.; Kim, K.; Lee, H.; Kang, T.; Cho, S.B.; Park, Y.; Cho, K.H. High-spatial resolution monitoring of phycocyanin and chlorophyll-a using airborne hyperspectral imagery. Remote Sens. 2018, 10, 1180. [CrossRef]

21. Becker, R.H.; Sayers, M.; Dehm, D.; Shuchman, R.; Quintero, K.; Bosse, K.; Sawtell, R. Unmanned aerial system based spectroradiometer for monitoring harmful algal blooms: A new paradigm in water quality monitoring. J. Great Lakes Res. 2019, 45, 444-453. [CrossRef]

22. Kutser, T.; Metsamaa, L.; Strömbeck, N.; Vahtmäe, E. Monitoring cyanobacterial blooms by satellite remote sensing. Estuar. Coast. Shelf Sci. 2006, 67, 303-312. [CrossRef]

23. Becker, R.H.; Sultan, M.I.; Boyer, G.L.; Twiss, M.R.; Konopko, E. Mapping cyanobacterial blooms in the Great Lakes using MODIS. J. Great Lakes Res. 2009, 35, 447-453. [CrossRef]

24. Kudela, R.M.; Palacios, S.L.; Austerberry, D.C.; Accorsi, E.K.; Guild, L.S.; Torres-Perez, J. Application of hyperspectral remote sensing to cyanobacterial blooms in inland waters. Remote Sens. Environ. 2015, 167, 196-205. [CrossRef]

25. Kim, H.-M.; Yoon, H.-J.; Jang, S.W.; Kwak, S.N.; Sohn, B.Y.; Kim, S.G.; Kim, D.H. Application of unmanned aerial vehicle imagery for algal Bloom monitoring in river Basin. Int. J. Control Autom. 2016, 9, 203-220. [CrossRef]

26. Sayers, M.; Fahnenstiel, G.L.; Shuchman, R.A.; Whitley, M. Cyanobacteria blooms in three eutrophic basins of the Great Lakes: A comparative analysis using satellite remote sensing. Int. J. Remote Sens. 2016, 37, 4148-4171. [CrossRef]

27. Beck, R.; Zhan, S.; Liu, H.; Tong, S.; Yang, B.; Xu, M.; Ye, Z.; Huang, Y.; Shu, S.; Wu, Q. Comparison of satellite reflectance algorithms for estimating chlorophyll-a in a temperate reservoir using coincident hyperspectral aircraft imagery and dense coincident surface observations. Remote Sens. Environ. 2016, 178, 15-30. [CrossRef]

28. Clark, J.M.; Schaeffer, B.A.; Darling, J.A.; Urquhart, E.A.; Johnston, J.M.; Ignatius, A.R.; Myer, M.H.; Loftin, K.A.; Werdell, P.J.; Stumpf, R.P. Satellite monitoring of cyanobacterial harmful algal bloom frequency in recreational waters and drinking water sources. Ecol. Indic. 2017, 80, 84-95. [CrossRef]

29. Binding, C.E.; Greenberg, T.A.; McCullough, G.; Watson, S.B.; Page, E. An analysis of satellite-derived chlorophyll and algal bloom indices on Lake Winnipeg. J. Great Lakes Res. 2018, 44, 436-446. [CrossRef]

30. Sawtell, R.W.; Anderson, R.; Tokars, R.; Lekki, J.D.; Shuchman, R.A.; Bosse, K.R.; Sayers, M.J. Real time HABs mapping using NASA Glenn hyperspectral imager. J. Great Lakes Res. 2019, 45, 596-608. [CrossRef] 
31. Parsons, D.R.; Jackson, P.R.; Czuba, J.A.; Engel, F.L.; Rhoads, B.L.; Oberg, K.A.; Best, J.L.; Mueller, D.S.; Johnson, K.K.; Riley, J.D. Velocity Mapping Toolbox (VMT): A processing and visualization suite for moving-vessel ADCP measurements. Earth Surf. Process. Landf. 2013, 38, 1244-1260. [CrossRef]

32. Ostrovsky, I.; Sukenik, A.; Yacobi, Y.Z.; Katsnelson, B.; Uzhanskii, E.; Moses, W.J.; Migdal, I. Hydroacoustic assessment of spatiotemporal dynamics of toxic cyanobacterium Microcystis: The role of physical factors in bloom formation. In Proceedings of the UACE2017, 4th Underwater Acoustics Conference and Exhibition, Skiathos, Greece, 2-7 September 2017; pp. 81-86.

33. Kanungo, T.; Mount, D.M.; Netanyahu, N.S.; Piatko, C.D.; Silverman, R.; Wu, A.Y. An efficient k-means clustering algorithm: Analysis and implementation. IEEE Trans. Pattern Anal. Mach. Intell. 2002, 24, 881-892. [CrossRef]

34. Ord, J.K.; Getis, A. Local spatial autocorrelation statistics: Distributional issues and an application. Geogr. Anal. 1995, 27, 286-306. [CrossRef]

35. Getis, A.; Ord, J.K. The analysis of spatial association by use of distance statistics. In Perspectives on Spatial Data Analysis; Springer: Berlin/Heidelberg, Germany, 2010; pp. 127-145.

36. Anselin, L. Local indicators of spatial association-LISA. Geogr. Anal. 1995, 27, 93-115. [CrossRef]

37. Choi, H.-W.; Kim, K.-H.; Lee, C.-Y. Application of Spatial Autocorrelation for the Spatial Distribution Pattern Analysis of Marine Environment-Case of Gwangyang Bay. J. Korean Assoc. Geogr. Inf. Stud. 2007, 10, 60-74.

38. Kang, J.-H.; Kim, Y.-K.; Yeon, M.-H. Application of Spatial Autocorrelation for Analysis of Spatial Distribution Characteristics of Birds Observed in Namdaecheon River, Muju-gun, Jeollabuk-do, Korea. J. Environ. Impact Assess. 2013, 22, 467-479. [CrossRef]

39. Yang, X.; Chen, X.R.; Li, Y.T. Research on Dynamic K-Means Clustering Algorithm in Cyanobacteria Blooms Detection. Appl. Mech. Mater. 2012, 157, 428-432. [CrossRef]

40. Huang, J.; Zheng, H.; Wang, H.; Jiang, X. Machine learning approaches for cyanobacteria bloom prediction using metagenomic sequence data, a case study. In Proceedings of the 2017 IEEE International Conference on Bioinformatics and Biomedicine (BIBM), Kansas City, MO, USA, 13-16 November 2017; pp. 2054-2061.

41. Kim, J.S.; Seo, I.W.; Baek, D. Seasonally varying effects of environmental factors on phytoplankton abundance in the regulated rivers. Sci. Rep. 2019, 9, 1-12. [CrossRef]

42. Ding, L.; Chen, K.-L.; Liu, T.; Cheng, S.-G.; Wang, X. Spatial-temporal hotspot pattern analysis of provincial environmental pollution incidents and related regional sustainable management in China in the period 1995-2012. Sustainability 2015, 7, 14385-14407. [CrossRef]

43. Landers, M.N.; Straub, T.D.; Wood, M.S.; Domanski, M.M. Sediment Acoustic Index Method for Computing Continuous Suspended-Sediment Concentrations; US Geological Survey: Reston, VA, USA, 2016.

44. Anselin, L.; Bera, A.K. Introduction to spatial econometrics. In Handbook of Applied Economic Statistics; CRC Press: London, NY, USA, 1998; pp. 237-291.

45. Anselin, L.; Syabri, I.; Kho, Y. GeoDa: An introduction to spatial data analysis. In Handbook of Applied Spatial Analysis; Springer: Berlin/Heidelberg, Germany, 2010; pp. 73-89.

46. Legendre, P. Spatial autocorrelation: Trouble or new paradigm? Ecology 1993, 74, 1659-1673. [CrossRef]

47. Rhee, D.S.; Do Kim, Y.; Kang, B.; Kim, D. Applications of unmanned aerial vehicles in fluvial remote sensing: An overview of recent achievements. KSCE J. Civ. Eng. 2018, 22, 588-602. [CrossRef]

Publisher's Note: MDPI stays neutral with regard to jurisdictional claims in published maps and institutional affiliations.

(C) 2020 by the authors. Licensee MDPI, Basel, Switzerland. This article is an open access article distributed under the terms and conditions of the Creative Commons Attribution (CC BY) license (http://creativecommons.org/licenses/by/4.0/). 